\title{
DEVE A INTEGRIDADE VINCULAR O PODER LEGISLATIVO? UMA ANÁLISE DAS CRÍTICAS DE ANDREI MARMOR À INTEGRIDADE LEGISLATIVA EM RONALD DWORKIN
}

\section{SHOULD THE VALUE OF INTEGRITY BIND THE LEGISLATURE? AN ANALYSIS OF ANDREI MARMOR'S CRITICISM ON LEGISLATIVE INTEGRITY IN RONALD DWORKIN}

\author{
Thomas da Rosa de Bustamante \\ Universidade Federal de Minas Gerais - UFMG (Belo Horizonte, MG, Brasil) \\ Christina Vilaça Brina \\ Universidade Federal de Minas Gerais - UFMG (Belo Horizonte, MG, Brasil)
}

Recebimento: 10 ago. 2016

Aceitação: 20 fev. 2017

Como citar este artigo / How to cite this article (informe a data atual de acesso / inform the current date of access):

BUSTAMANTE, Thomas da Rosa de; BRINA, Christina Vilaça. Deve a integridade vincular o poder legislativo? Uma análise das críticas de Andrei Marmor à integridade legislativa em Ronald Dworkin. Revista da Faculdade de Direito UFPR, Curitiba, PR, Brasil, v. 62, n. 1, jan./abr. 2017, p. 137 - 153. ISSN 2236-7284. Disponível em: $<$ http://revistas.ufpr.br/direito/article/view/47835>. Acesso $\quad$ em: $30 \quad$ abr. $2017 . \quad$ DOI: http://dx.doi.org/10.5380/rfdufpr.v62i1.47835.

\section{RESUMO}

O presente artigo busca analisar a possibilidade de vinculação do poder legislativo à ideia de integridade defendida por Ronald Dworkin. Como o citado autor afirma, a integridade política deve ser aplicada tanto ao âmbito legislativo quanto ao judiciário, estando em ambos os casos pautada pela coerência. Em contraposição, são apresentadas as ideias defendidas por Andrei Marmor, que, embora não negue a importância da integridade e da coerência, argumenta que o poder legislativo não pode ser a elas vinculado. Ademais, será apresentado sucintamente o posicionamento de Jeremy Waldron, também em defesa da integridade.

\section{PALAVRAS-CHAVE}

Integridade. Legislação. Dworkin. Marmor.

\begin{abstract}
This essay intends to analyze the possibility of binding the legislature to the ideal of integrity defended by Ronald Dworkin. As this author asserts, political integrity should be applied both to the legislature to the judiciary, and in both cases, it is based on coherence. Against this view, we present Andrei Marmor's opinion. Although Marmor does not deny the importance of coherence and integrity, he claims that the legislative branch cannot be bound by this political value. Finally, we introduce Jeremy Waldron's view, which indirectly responds to Marmor and offers a defense of integrity.
\end{abstract}

\section{KEYWORDS}

Integrity. Legislation. Dworkin. Marmor. 


\section{INTRODUÇÃO}

A teoria de Dworkin é perpassada pelo conceito de integridade e, consequentemente, pela noção de coerência, que está a ela diretamente relacionada.

A ideia de coerência por ele defendida parece, à primeira vista, muito plausível, mas uma análise mais pormenorizada das implicações por ela trazidas faz surgirem críticas à sua aplicação. Sem embargo, ela pode enfrentar importantes objeções ao pretender ser aplicada no âmbito da política e da produção da lei (pelo poder legislativo). Diante dessas objeções, pretendemos demonstrar o que há de plausível e implausível neste ideal político, a partir de uma reflexão sobre os comentários de autores como Andrei Marmor e Jeremy Waldron sobre o ideal dworkiniano de “integridade legislativa”.

Sob a metodologia de uma análise bibliográfica e uma atitude reflexivo-compreensiva dos valores políticos fundamentais para estabelecer a legitimidade do direito, iniciaremos com uma discussão da concepção de Dworkin sobre a integridade e das principais objeções que ela despertou nos escritos de Andrei Marmor, que se posiciona contrariamente à ideia de integridade no âmbito do legislativo. Após essa reflexão, exporemos sucintamente a opinião de Jeremy Waldron e os argumentos que podem ser utilizados para interpretar a própria noção de integridade em sua melhor luz. Por derradeiro, pretendemos, na seção final, fazer uma valoração própria das críticas de Marmor à teoria de Dworkin, com o fito de entender a sua força concreta na argumentação jurídica e na interpretação do direito.

\section{A CRÍTICA DE ANDREI MARMOR À NOÇÃO DE “INTEGRIDADE” NO ÂMBITO LEGISLATIVO}

No livro O Império do Direito, Dworkin sugere que possuímos dois princípios de integridade política - um princípio legislativo, que requer que os legisladores tentem fazer com que todas as leis sejam coerentes moralmente, e um princípio relacionado à jurisdição, que instrui que o direito seja interpretado em sua aplicação prática de maneira coerente, na forma mais ampla possível. Partindo desses pressupostos, Marmor tentará argumentar, em seu artigo Should We Value Legislative Integrity?, que o primeiro desses princípios, ou seja, o que se refere à integridade legislativa, não é um ideal ou, ao menos, não um ideal importante a ser alcançado (MARMOR, 2006, p. 125).

Algumas pessoas tendem a valorizar a coerência simplesmente pelo fato de que teorias incoerentes não podem ser verdadeiras. Independentemente do que se entenda por coerência, ela está relacionada ao fato de se evitar contradições. Nem todo grupo consistente de preposições é coerente, 
mas todo grupo inconsistente de proposições é necessariamente incoerente. Caso esta afirmativa esteja correta, podemos concluir que a falta de coerência não necessariamente leva à contradição, embora o contrário seja verdadeiro. Um grupo inconsistente de proposições é, ipso facto, incoerente. Marmor aduz que a razão dessa conclusão é muito simples: coerência deve significar algo além da mera falta de consistência. Quando lidamos com a coerência temos em mente um grupo de proposições que de alguma forma se sustenta mutuamente. A partir dessa análise, Marmor busca demonstrar que uma teoria, ou grupo de proposições, pode falhar em sua coerência ainda que não possua contradições evidentes. Portanto, não se pode aduzir que um grupo incoerente de proposições é necessariamente falso (MARMOR, 2006, p. 126).

Essa reflexão parece encontrar amparo, também, na relação que Dworkin estabelece entre “integridade” e “consistência”. Para este autor, a integridade "exige que os padrões públicos da comunidade sejam tanto construídos como observados, tanto quanto possível, de modo a expressar um único esquema coerente acerca da justiça e da equidade em sua correta relação” (DWORKIN, 1986, p. 219, tradução nossa). A integridade significa que o direito sempre deve ser criado ou interpretado de forma a criar um todo integral e consistente (GUEST, 2012, p. 78). Para além da mera ideia de consistência, a integridade é sempre uma questão de princípio, e não exige apenas uma simples forma de coerência no âmbito da elaboração das políticas. Pelo contrário, no âmbito legislativo (que é o que nos interessa neste trabalho), o princípio da integridade "exige que a legislatura busque proteger para todos o que ela considere serem os seus direitos morais e políticos, de modo que os padrões públicos expressem um esquema de justiça e equidade coerente” (DWORKIN, 1986, p. 221, tradução nossa).

Marmor questiona se há na integridade política algo além da exigência de que a lei seja feita de forma coerente. E, para este questionamento, afirma que Dworkin entende a coerência de forma mais abrangente que a integridade política, e não o contrário. A integridade política requer que o direito seja criado de forma moralmente coerente (MARMOR, 2006, p. 127). A integridade, para Dworkin, exige do intérprete um tipo especial de responsabilidade em relação ao passado e aos propósitos que dirigem e justificam a prática que se pretende interpretar. O sujeito

\footnotetext{
deve interpretar o que aconteceu antes porque ele tem uma responsabilidade de avançar a empreitada em questão em vez de seguir em uma direção própria. Portanto ele deve determinar, de acordo com o seu próprio juízo, o que as decisões anteriores significam, qual é o propósito ou o tema que ela possui, considerados conjuntamente (DWORKIN, 1985, p. 159, tradução nossa, grifo do autor).
}

É possível que o direito seja pragmaticamente incoerente sem que isso fira o princípio da integridade. Por exemplo, o direito pode ser pragmaticamente incoerente na medida em que incentive 
comportamentos que, a partir de determinado ponto de vista pragmático, como políticas econômicas ou ambientais, sejam de algum modo incoerentes (MARMOR, 2006, p. 127).

Podemos supor, então, que a lei seja moralmente incoerente se suas diversas prescrições e suas justificações subjacentes não puderem ser subsumidas sob uma teoria moral coerente. Ou, poderíamos dizer que, nesses casos, não há um único agente moral racional concebível cujo ponto de vista moral poderia justificar todo o conjunto de prescrições em consideração. Marmor acredita que é basicamente essa suposição o que Dworkin defende como o valor da integridade no direito (MARMOR, 2006, p. 127).

Entretanto, o famoso exemplo de Dworkin do que constituiria a violação da integridade na legislação não se adequa ao significado de integridade que ele defende. Dworkin pede que imaginemos o que ele chama de legislação do tipo “checkerboard”, o que poderia ser verificado, por exemplo, em uma legislação que prescreva que abortos são legalmente permitidos para mulheres que tenham nascido em dias pares e proibido para mulheres que tenham nascido em dias ímpares. Para Dworkin, esse tipo de legislação deve ser considerado inaceitável, pois há violação à integridade do direito. Não haveria, para Dworkin, um único agente moral que poderia justificar uma tal solução como um compromisso coerente de considerações conflitantes no que diz respeito à admissibilidade do aborto. Marmor, contudo, considera o exemplo apresentado um exemplo ruim, pois não precisamos recorrer à integridade ou à coerência para explicar o que há de errado nessas leis do tipo “checkerboard”. O que há de errado nelas é o fato de que não há boas razões que as suportem. Caso não haja boas razões para o tratamento diferenciado para mulheres nascidas em dias ímpares e pares, então a lei é ruim, pois não possui razão que a sustente (MARMOR, 2006, p. 127).

Em determinados casos, é possível que haja escolhas arbitrárias na criação das leis, mas para que isso seja aceitável devem existir boas razões para essa escolha arbitrária. O problema com o exemplo do aborto é precisamente que esse caso é o tipo de situação em que não há nenhuma boa razão para que haja um ponto de corte arbitrário (MARMOR, 2006, p. 127).

Marmor admite, contudo, que nenhum dos argumentos por ele apresentados significa que a integridade legislativa seja um conceito vazio. O legislador possui inúmeras formas de criar leis moralmente incoerentes. O ponto defendido por Marmor é simplesmente o fato de que a legislação “checkerboard” descrita por Dworkin não é uma dessas formas de criação de leis moralmente incoerentes. Uma lei que não é sustentada por uma boa razão é ruim simplesmente pelo fato de não ser sustentada por uma boa razão. A lei é moralmente incoerente, violando o ideal de integridade, quando as várias normas ou prescrições que encarna são, de alguma forma, moralmente contraditórias. Marmor ressalta que nem toda tensão ou conflito potencial entre princípios morais 
equivale a uma incoerência, visto que toda doutrina moral abrange inúmeras tensões e conflitos na aplicação de seus princípios e ideias (MARMOR, 2006, p. 128).

Marmor afirma haver diferenças entre conflitos e contradições. Para ele, uma contradição entre princípios claramente viola o requisito de coerência e a questão que se coloca é se um conflito entre princípios pode ser incoerente, mesmo não sendo contraditório. Segundo Marmor, presumivelmente, a resposta é sim. Como já foi observado anteriormente, a coerência deve significar algo mais do que a mera consistência lógica. Por isso, há concepções morais ou visões de mundo que simplesmente não podem ser reunidos sob uma doutrina coerente, mesmo quando o conjunto total de proposições em que se acredita não seja logicamente inconsistente (MARMOR, 2006, p. 128-129).

Marmor divide a incoerência moral relevante para o ideal de integridade legislativa em dois tipos: um tipo deriva da fragmentação dos valores dentro de uma determinada doutrina moral abrangente, denominado por Marmor de incoerência interna, e o outro, do pluralismo razoável (termo rawlsiano deliberadamente utilizado por Marmor), denominado por ele de incoerência externa. A incoerência interna resulta da complexidade das fontes de pensamento moral. Assim, toda teoria moral abrangente acaba sendo, em certa medida, incoerente. Nossas preocupações morais e éticas não respondem a uma única pergunta - refletem uma miríade de preocupações humanas, algumas privadas e individuais, outras públicas e sociais. Dessa forma, mostra-se pouco provável que sejamos capazes de construir toda uma cosmovisão moral e ética capaz de subsumir todas as preocupações divergentes no âmbito de um conjunto coerente de princípios (MARMOR, 2006, p. 129).

A ideia de coerência externa é resultado de um fato diferente sobre a complexidade moral do nosso mundo: o pluralismo razoável. Na maioria das sociedades contemporâneas há um conjunto abrangente de doutrinas morais que, por um lado, são moralmente inconsistentes, mas, por outro, encontram-se dentro dos limites de desacordo razoável. Marmor ressalta a importância de termos em mente a existência de uma diferença entre a pluralidade de doutrinas morais e o pluralismo de valores (value pluralism). Nem toda pluralidade de doutrinas morais envolve conflitos profundos, mesmo que as doutrinas sejam mutuamente excludentes. A escolha de uma dessas doutrinas pode simplesmente refletir uma escolha entre conjuntos de valores, não implicando necessariamente conflitos profundos. Por outro lado, quando se fala de pluralismo de valores, referimo-nos a conflitos morais ou éticos profundos (MARMOR, 2006, p. 129-130). Joseph Raz parece concordar com o posicionamento adotado por Marmor, ao afirmar que a imposição de coerência à totalidade do direito é equivocada em dois importantes aspectos. Primeiramente, as explicações baseadas na coerência global subestimam as implicações do pluralismo de valores, visto que a moral não constitui um sistema, mas uma pluralidade de princípios independentes. Em segundo lugar, a coerência tenta 
petrificar ou minimizar os efeitos da política, porém, não há motivos para petrificá-los ou minimizálos (RAZ, 1994, p. 336-337).

Nesse contexto, Marmor apresenta dois pressupostos: primeiro, pessoas racionais possuem desacordos razoáveis sobre valores éticos e morais fundamentais; segundo, a ideia de pluralismo razoável não deriva necessariamente, nem implica necessariamente, o ceticismo moral. Nesse sentido, Marmor apresenta dois motivos para que se defenda o pluralismo razoável: o pluralismo moral pode refletir uma visão sobre a natureza da moralidade e os limites do conhecimento moral, além de poder ser uma visão política sobre os limites da autoridade coercitiva do Estado (MARMOR, 2006, p. 130).

Marmor aduz que há duas formas que podemos explorar o valor da integridade legislativa. O primeiro, e provavelmente o argumento mais importante, tenta demonstrar que a ideia de integridade legislativa está diretamente em desacordo com o valor do pluralismo e com o comprometimento com um Estado liberal que respeite o pluralismo razoável. No segundo argumento, Marmor afirma explorar as causas que levaram ao fracasso da integridade legislativa em legislaturas democráticas, argumentando que não há nada a se lamentar sobre essas causas, havendo, pelo contrário, motivos para recomendá-las (MARMOR, 2006, p. 130).

O principal argumento apresentado por Marmor contra o ideal da integridade da legislação baseia-se em dois pontos: um ideal político-moral, inspirado por John Rawls, e uma observação que na verdade rejeita parte da posição de Rawls sobre o assunto. O ideal político-moral é o requisito de que uma sociedade bem ordenada tente inibir a criação de leis em que doutrinas morais sejam potencialmente controversas e sujeitas a um desacordo razoável entre vários segmentos da população. Esse ideal não deve se confundir com o ideal de imparcialidade proposto por Rawls, sendo um princípio mais modesto, uma vez que o Estado não seria capaz de se manter neutro entre concepções de bem e de moralidade (MARMOR, 2006, p. 131).

Como afirmado por Marmor, a maior parte das controvérsias jurídicas/políticas centram-se na questão do que é, ou não é, um fundamento constitucional. Além disso, não há nenhuma maneira prática de remover, da agenda jurídica/política, questões que sejam extremamente polêmicas ou controversas pelo simples fato de serem polêmicas ou controversas. Mesmo se admitirmos que determinados aspectos do direito constitucional podem ser confinados às restrições da razão pública, essas restrições não podem ser aplicadas à legislação como um todo. Esse fato não é surpreendente, pois o direito reivindica a autoridade para regular qualquer tipo de comportamento em todas as esferas da vida. Mesmo quando o direito se abstém de intervir em determinado âmbito já houve um julgamento de que o direito não deve intervir. Assim, deve-se ter em mente que a função essencial do 
direito é resolver conflitos na sociedade, e não há limites inerentes sobre os tipos de conflitos que possam surgir e que precisem de algum tipo de regulamentação legal (MARMOR, 2006, p. 132).

Nesse sentido, Marmor afirma concordar mais com a visão de direito defendida por Dworkin, do direito como um "império" abrangente que potencialmente alcança todos os aspectos de nossas vidas, por considerá-la mais realista que o ideal de Rawls, de uma esfera isolada da razão pública (MARMOR, 2006, p. 132).

Retornando à questão anterior da necessidade de respeito ao pluralismo razoável, Marmor afirma ser esta a razão de se abster de esposar o ideal da integridade legislativa, pois qualquer tentativa de se impor uma integridade moral estrita sobre o direito poria em causa a fragmentação moral de uma sociedade pluralista. Quanto mais se deseja que uma integridade moral seja implementada pelo direito, mais devemos esperar que isso implemente um único ponto de vista moral. A ideia de integridade na legislação basicamente adotaria a estratégia pela qual “o vencedor leva tudo”, que é diretamente contrária ao respeito pelo pluralismo razoável. Com isso, uma certa fragmentação moral dos valores e uma certa incoerência são inescapáveis se desejamos respeitar o pluralismo (MARMOR, 2006, p. 132-133).

O principal ponto com relação ao respeito ao pluralismo de valores é que não se quer ter um sistema jurídico/político em que o vencedor (seja a decisão da maioria ou da suprema corte) imponha seus pontos de vista morais a todo o resto da população. Além disso, mesmo dentro de uma única doutrina moral abrangente não há como impor a coerência sem que haja uma perda considerável da sutileza e complexidade das preocupações morais relevantes. Marmor ressalta, contudo, que seu ponto de vista pode ser defendido ainda que se ignore o problema da coerência interna e, por isso, ele afirma que não irá se esforçar em defender essa afirmação mais forte (MARMOR, 2006, p. 133).

Segundo Marmor, Dworkin defende o dever de lealdade para com a comunidade como premissa da integridade política, e esse dever gera uma obrigação de obediência à lei, que deve ser vista como a voz organizada da sociedade tomada como um todo. A partir disso, Dworkin apresentou a necessidade de se assumir uma personificação do direito, como se o direito devesse falar uma única voz, manifestando a decisão coletiva da comunidade (MARMOR, 2006, p. 133).

Marmor discorda dessa ideia defendida por Dworkin, de que uma sociedade democrática bem organizada pode, e deve, ser vista como uma comunidade, e suas leis percebidas como decisões coletivas dessa comunidade, pois essa ideia estaria diretamente em desacordo com a necessidade de respeito ao pluralismo razoável. Uma sociedade política não poderia falar com uma única voz sobre a moral, pois essa voz é essencialmente fragmentada e, entendida como um todo, profundamente 
incoerente. Tentar impor a coerência apenas permitiria que algumas doutrinas se impusessem a outras, o que não é um ideal liberal (MARMOR, 2006, p. 133).

Marmor concorda com o insight rawlsiano de que uma sociedade liberal bem organizada deve respeitar o pluralismo e, para isso, deve evitar que o Estado implemente qualquer compreensão moral particular ou doutrina religiosa. Entretanto, não acredita que se possa implementar um princípio de neutralidade, que designe uma esfera de razão pública que enclausure a legislação com rigorosos limites de neutralidade, pois o direito é inevitavelmente abrangente e não há como impedir que regule áreas da vida que sejam moral ou eticamente controversas. Portanto, conclui que seria errado insistir em um ideal de integridade legislativa, visto que não se deve esperar que a lei possua uma única voz capaz de abranger a gama de doutrinas morais existentes nos vários segmentos da sociedade (MARMOR, 2006, p. 133-134).

Segundo Marmor, podem surgir duas réplicas aos argumentos apresentados por ele. A primeira, de que ele não demonstrou que a integridade não possua méritos, e a segunda, de que a integridade poderia incorporar o valor do pluralismo como um dos ingredientes em um ponto de vista moral complexo que compreenda um conjunto de valores de primeira ordem e um valor de segunda ordem que exija o respeito ao pluralismo. Assim, quando falar a uma só voz, será uma voz que leve em conta a necessidade de respeitar os pontos de vista de outras pessoas, mesmo que discordantes (MARMOR, 2006, p. 134).

Contra as possíveis réplicas, Marmor rebate aduzindo que de fato não demonstrou que não há razões para afirmar que a integridade possa possuir méritos, mas que isso não é essencial para demonstrar que há razões para não se adotar a integridade legislativa. Marmor assume, ainda, que essas razões nem sempre estão presentes, em parte porque o valor do pluralismo possui seus próprios limites, e em parte porque pode haver casos em que o pluralismo não esteja em jogo. A necessidade de respeito ao valor do pluralismo conta fortemente contra o ideal da integridade legislativa, e isso deve ser suficiente para demonstrar que não há razões para seguir a integridade legislativa como um ideal, ou seja, esperar que o direito seja o mais coerente possível (MARMOR, 2006, p. 134).

Considerando o segundo contra-argumento, que sugere que mesmo que se leve em conta a necessidade de respeitar o pluralismo, o direito deve possuir uma única voz, que já deverá incorporar a necessidade de respeito ao pluralismo, Marmor argumenta que, caso haja um verdadeiro conflito entre o respeito ao pluralismo e a integridade legislativa, é necessário o respeito ao pluralismo de valores como uma forma de restrição externa na busca por uma moralidade compreensiva (comprehensive morality) (MARMOR, 2006, p. 134-135). 
Para Marmor, há diversas causas para que a integridade legislativa fracasse além da possibilidade de que os legisladores simplesmente cometam um erro. A incoerência da legislação resulta, por vezes, do grande número de instituições legislativas e dos meios limitados de coordenação, por uma autoridade central, dos vários atos legislativos. Essa incoerência não advém apenas do número elevado de instituições legislativas, mas também das divergências nos papéis sociais e políticos por elas desempenhados (MARMOR, 2006, p. 135).

O bom funcionamento de uma democracia pressupõe a criação de uma complexa divisão do poder legislativo em diferentes instituições, algumas com maior e outras com menor limitação em sua autoridade. Marmor assume que esta divisão é necessária, pois é uma salvaguarda contra tiranias e proporciona uma maior diversidade de metas, promovendo uma maior diversidade de interesses. Não se pode presumir, contudo, que essa divisão do poder legislativo em diferentes instituições seja propositalmente projetada para comprometer a integridade da legislação. Entretanto, quanto maior a divisão de poder legislativo entre diferentes instituições que, por vezes, possuem interesses conflitantes, menores as chances de sucesso da integridade legislativa. Observa-se, com isso, que o fracasso da integridade legislativa deriva de aspectos de nossas instituições políticas que, por sua vez, estão baseados em princípios morais e políticos robustos (sound moral-political principles) (MARMOR, 2006, p. 136).

Não se pode negar que existe um certo nível de coerência e de coordenação legislativa mínima, essenciais ao bom funcionamento de um sistema jurídico. Esse mínimo necessário de coerência para que o direito funcione, entretanto, não consubstancia o ideal de integridade legislativa. É necessário um nível mínimo de estabilidade no direito, mas isso não quer dizer que o direito deva ser o mais estável possível, ou seja, a estabilidade não deve ser buscada como um ideal para o direito (MARMOR, 2006, p. 136).

A falta de legitimidade na legislação é, portanto, um resultado da multiplicidade de instituições legislativas com diferentes metas. Entretanto, mesmo com um corpo legislativo único, há diversas estratégias utilizadas pelos legisladores que tendem a minar a integridade legislativa, como as barganhas e compromissos assumidos pelos legisladores para obterem a aprovação de determinadas leis, pois acabam resultando em leis moralmente incoerentes (MARMOR, 2006, p. 136). Nesse ponto, Marmor mostra estar atento à realidade vivida constantemente nas instituições legislativas das mais variadas sociedades.

Segundo ele, há basicamente dois principais tipos de compromisso que são assumidos pelos legisladores. Ou se abre mão de um pouco do que se quer alcançar, ou se tem tudo, mas é necessário dar à outra parte um pouco do que ela almeja, que pode estar relacionado ou não ao que se pretende 
obter. Em ambas as situações a questão sobre a coerência moral ou não do resultado do compromisso assumido depende de vários detalhes específicos, que não foram objeto do estudo de Marmor. Marmor afirma ser suficiente saber que os compromissos e troca de favores podem resultar em uma legislação que fica muito aquém do ideal de integridade legislativa (MARMOR, 2006, p. 136).

Embora a prática de compromissos entre legisladores possa parecer condenável em uma sociedade democrática, outras alternativas podem ser ainda piores. Marmor afirma que um partido que não precise fazer compromissos com outros partidos possui poder demasiado, pois possui poder suficiente para implementar sua moral e agenda política sem precisar prestar suficiente atenção nas necessidades e interesses daqueles que se opõem a suas doutrinas ou cujos interesses se opõem aos seus. Há, portanto, um delicado equilíbrio entre o poder político partidário em demasia e o insuficiente. Caso a maioria dominante seja muito frágil e o governo necessite fazer compromissos em cada passo que tente dar, o ato de governar estará seriamente comprometido, mas isso não quer dizer que a situação oposta seria a ideal. Um bom governo não é aquele que não precisa fazer compromissos com minorias partidárias. Nesse sentido, em uma sociedade pluralista compromissos não são necessariamente lamentáveis, mas uma virtude democrática importante na tomada de decisões (MARMOR, 2006, p. 136-137).

Em democracias o controle do governo passa pelas mãos de diferentes partidos periodicamente, e normalmente aquele que assume o poder busca implementar seus ideais produzindo novas leis que efetivem seus pontos de vista. Contudo, aquele que assume o poder não começa uma história em branco, pois encontra diversas leis que foram produzidas anteriormente por diferentes governos, que podem ser contrárias a seus pontos de vista político-morais. Essas são as circunstâncias de realinhamentos partidários, e geram mudanças legislativas que são moralmente incoerentes. Assim, leis e princípios novos e antigos coexistem muitas vezes de forma conflitante. O fracasso da integridade legislativa, segundo Marmor, ocorre tanto por razões práticas quanto por razões de princípio. Ainda que os novos governos quisessem revogar todas as leis e políticas anteriores incompatíveis com seus ideais, a grande quantidade de legislação e sua complexidade tornaria a tarefa impraticável. Os governos também não devem tomar essa atitude devido a princípios, como os da estabilidade e da continuidade (MARMOR, 2006, p. 137).

Evidentemente a legislação pode ser alterada, mas há um mínimo de estabilidade exigido para que o direito mantenha sua força, visto que as pessoas normalmente ajustam seus comportamentos e expectativas de acordo com o direito vigente. Mudanças repentinas de grande parte da legislação necessitariam de um período de adaptação da população, o que poderia gerar comoção e grandes rupturas na ordem vigente (MARMOR, 2006, p. 137). 
Marmor ressalta que, no presente contexto, um reconhecimento geral de que o realinhamento partidário não deve envolver uma tentativa de revogar os princípios existentes e as leis produzidas por outros governantes também decorre do princípio de respeito ao pluralismo (MARMOR, 2006, p. 138).

Quando determinado partido sai do poder, os ideais por ele defendidos continuam a representar parte da sociedade e, por isso, revogar as leis por ele implementadas seria um desrespeito ao pluralismo. Existe um delicado equilíbrio que deve ser respeitado: de um lado uma vitória eleitoral que resulte em realinhamento partidário é certamente um apelo à mudança, mas isso não deve ser concebido como uma permissão para ignorar as convicções morais e políticas daqueles que perderam (MARMOR, 2006, p. 138).

Nesse sentido, Marmor conclui seu artigo afirmando que as circunstâncias de realinhamento partidário promovem uma quantidade considerável de incoerência legislativa. O novo governo é tipicamente forçado a introduzir mudanças legislativas que podem ser conflitantes com a legislação já existente. Essas circunstâncias produzem uma miscelânea de leis que não seria capaz de refletir um único ponto de vista ético e moral que seja moralmente coerente. Uma legislação incoerente, entretanto, não deve ser vista como indesejável, pois reflete considerações políticas e morais que são sustentadas por razões de princípio. Essas razões derivam da necessidade de se manter um certo nível de estabilidade jurídica e de se respeitar o pluralismo de valores. O realinhamento partidário requer um compromisso delicado entre considerações concorrentes. Ademais, nem todo compromisso é lamentável, como é o caso dos compromissos que manifestam respeito pela complexidade moral de nossa realidade política e social.

\section{A VALORAÇÃO DA CRÍTICA: DA INTEGRIDADE À RESPONSABILIDADE}

Antes de valorar, positiva ou negativamente, as críticas de Marmor à aplicação, no âmbito legislativo, do ideal de integridade - tal como definido por Dworkin -, é necessário entender qual é a natureza do valor "integridade" e como esse valor se relaciona com a equidade e a justiça.

Em O Império do Direito, Dworkin parece entender a justiça, a equidade e a integridade como três valores políticos independentes, que podem eventualmente entrar em conflito e exigir que um seja parcialmente sacrificado com o objetivo de fomentar o outro (DWORKIN, 1986, p. 178). Esse entendimento, no entanto, torna parcialmente obscuro e potencialmente incoerente o pensamento de Dworkin acerca da integridade, como aponta Jeremy Waldron em um comentário predominantemente simpático à visão de Dworkin sobre o assunto, que visa estabelecer quais são as 
circunstâncias em que o valor da integridade se torna útil e aplicável para resolver as nossas desavenças sobre a justiça.

Para Waldron, a forma como Dworkin relaciona os valores da justiça, da equidade (fairness) e da integridade está baseada em um “erro de categoria” (category mistake), consistente em caracterizar tais valores como “em certa medida independentes um do outro” (DWORKIN, 1986, p. 177, tradução nossa). Para Waldron, justiça e equidade (“fairness”) não são independentes no sentido propugnado por Dworkin. Pelo contrário, “um está funcionalmente relacionado com o outro”, pois “é tarefa da equidade política enfrentar a situação que surge quando as pessoas que vivem em sociedade não podem chegar a um acordo sobre a justiça, e, portanto, não podem agir inequivocamente como uma sociedade apenas com base em um apelo ao ideal de justiça” (WALDRON, 1999, p. 196, tradução nossa). Uma forma plausível de se entender o valor político da equidade seria, portanto, por meio da noção de “razões de segunda ordem” proposta por Joseph Raz (RAZ, 1999, p. 39). Tendo em vista que, para Waldron, a justiça tem um caráter necessariamente social - uma vez que "é algo que nós devemos assegurar conjuntamente, e ninguém pode fazer de maneira isolada” (WALDRON, 1999, p. 196, tradução nossa) -, sempre que ficar evidenciado que os participantes de um discurso público não compartilham um mesmo juízo sobre uma questão moral controvertida relativa à distribuição de bens sociais, a equidade gera uma "razão de segunda ordem para não agir peremptoriamente” com base apenas na sua própria valoração de razões de primeira ordem (WALDRON, 1999, p. 196, tradução nossa).

A equidade funcionaria, por conseguinte, como um critério de valoração para os procedimentos que adotamos para resolver questões de justiça. Ela não “compete” com a justiça porque ela própria é um parâmetro de segunda ordem para resolver problemas de justiça, e o mesmo se poderia dizer acerca do valor político da integridade. As denominadas “circunstâncias da integridade”, é dizer, o conjunto de condições sociais necessárias para que a integridade se torne aplicável, incluem a existência de um “desacordo acerca do que é justo e injusto”:

Por conseguinte, qualquer suposto trade-off entre a justiça e a integridade deixa sem resposta
a questão sobre qual visão controvertida acerca da justiça está sendo privilegiada em nossa
concepção sobre esse trade-off. Parece melhor dizer não que a justiça e a integridade entram
em conflito, mas que a integridade - assim como a equidade - é um valor político que se
aproxima de questões de justiça desde um ângulo oblíquo - um ângulo definido
funcionalmente pela necessidade de lidar com o fato de que várias decisões com as quais a
nossa comunidade já se comprometeu foram tomadas com base em concepções de justiça
divergentes e conflitantes (WALDRON, 1999, p. 198, tradução nossa).

A análise de Waldron sobre as circunstâncias da integridade revela, porém, uma compreensão, sobre a integridade, diferente da apresentada por Marmor em sua crítica ao ideal de 
integridade legislativa defendido por Dworkin. Para Waldron a ausência de integridade é, no sistema de Dworkin, a própria razão pela qual as denominadas “checkerboard laws” devem ser consideradas injustas ou, nas palavras de Marmor, carentes de boas razões. A integridade não é um valor político independente e só se torna relevante na medida em que ela nos dá uma pauta adequada para avaliar a justiça ou a injustiça de determinada decisão política.

Se Waldron estiver correto, portanto, a crítica de Marmor a Dworkin não atinge o alvo pretendido, pois a integridade é ela própria um dos fatores de valoração necessários para que se possa afirmar que uma determinada lei carece ou não de boas razões. Uma falta de integridade é vista como um parâmetro de avaliação negativa do conteúdo de uma lei; a vulneração à integridade é tão grave quanto uma violação à exigência de equidade (fairness) nos procedimentos de deliberação seguidos para a aprovação dessa mesma lei. Raz afirma que, para Dworkin, a integridade aplicada ao legislativo irá, inclusive, distinguir o que é direito do que não é. Regras que não passam pelo teste da integridade não fazem parte do direito (RAZ, 2004, 287).

Se Dworkin estiver correto, portanto, Waldron acredita que dificilmente podem haver boas razões para se adotar qualquer lei que venha a constituir uma vulneração ao princípio da integridade.

O que importa avaliar, portanto, é se Dworkin está correto em sua defesa da pretensão de que a integridade constitui um parâmetro adequado para avaliar as nossas decisões sobre argumentos de princípio ou questões de justiça. Nesse contexto, o principal argumento de Dworkin em favor desse parâmetro é o seu ideal de “comunidade de princípios”, que está baseado na ideia de que todos os membros de uma comunidade política possuem obrigações associativas em virtude do seu status de membro dessa comunidade. As responsabilidades associativas ligam-se ao ideal de cidadania e possuem quatro características principais: i) são obrigações especiais, que derivam do status de membro em determinada comunidade e valem distintamente para o grupo; ii) são inteiramente pessoais, na medida em que elas se vinculam diretamente a cada membro do grupo e protegem também a cada um desses membros; iii) instituem uma responsabilidade de consideração pelo bemestar de cada um dos membros do grupo; e iv) instituem não apenas um dever de consideração, mas de igual consideração por todos os membros (DWORKIN, 1986, p. 199-200).

O ideal da integridade, como manifestação dessas obrigações no âmbito da formulação das decisões coletivas, exige que "ninguém seja deixado de fora, que nós todos estejamos juntos na política, para o bem ou para o mal, e que ninguém deva ser sacrificado como os feridos abandonados no campo de batalha, em busca de uma cruzada por justiça” (DWORKIN, 1986, p. 213, tradução nossa). 
A pretensão de Dworkin, como se vê, é acomodar os juízos sobre a justiça e os direitos de cada um dos membros da comunidade, incluindo-se os vencidos, que devem ter suas convicções (de boa-fé) respeitadas pela comunidade e os seus valores de certa forma acomodados na elaboração das normas gerais. Dworkin não poderia admitir jamais, portanto, a possibilidade de um processo de decisão do tipo “winner takes all”, em que a parte vencida seria forçada a abrir mão dos seus valores, e nós (enquanto maioria) poderíamos “suprimir ou liquidar os que discordam de nós sobre a justiça” (WALDRON, 1999, p. 206, tradução nossa). Ao voltar-se contra a possibilidade de alguns de nós, cidadãos, serem “deixados para trás”, Dworkin tem em mente e condena

a possibilidade de que, depois da vitória que nós tenhamos obtido para os nossos princípios (em nossa opinião, os princípios de justiça verdadeiros), nós possamos tentar prevenir os princípios injustos, que os nossos oponentes tenham defendido, de exercer algum papel ou continuar a influenciar arranjos sociais (WALDRON, 1999, p. 206, tradução nossa).

Longe de eliminar o pluralismo característico das sociedades democráticas contemporâneas, Dworkin pretende com o ideal de integridade acomodar os diferentes valores em nossa comunidade e construir uma sociedade liberal em que cada um dos nossos juízos autônomos e de boa-fé sobre a moralidade política possa ser respeitado e incorporado em uma única teoria moral coerente e sensível à história institucional da nossa comunidade.

O ideal de integridade será considerado valioso, para Dworkin, enquanto perdurar o nosso sentimento de comunidade e o nosso propósito de seguirmos vivendo juntos como iguais em uma certa comunidade política. No entanto, é justamente essa capacidade que é questionada por Marmor no artigo que comentamos.

A crítica de Marmor à integridade é particularmente destrutiva, portanto, se for correta a sua conclusão de que a integridade é uma ameaça ao pluralismo político e moral existente em nossa comunidade e um alto preço político a pagar, pois dificulta a formulação de compromissos e mudanças de orientação política em nossa comunidade.

O ideal de integridade no âmbito legislativo, independentemente dos méritos que ele possa conservar no contexto da aplicação judicial do direito (adjudication) e na interpretação da constituição pelas cortes constitucionais, pode ser visto como uma exigência difícil de ser atendida pelo legislador democrático, já que mesmo no âmbito da moralidade política o modus operandi do poder legislativo mais relevante é e deve continuar a ser a negociação respeitosa e a busca por compromissos políticos com aqueles que advogam doutrinas compreensivas sobre a justiça diferentes das nossas. 
Nesse sentido, Marmor parece ter um bom argumento contra a resistência que Dworkin apresenta à formulação de acordos e compromissos no âmbito da deliberação pública, que pode ser exemplificada no seguinte parágrafo:

Mesmo quando o debate [parlamentar] é esclarecedor, o processo majoritário incentiva compromissos que podem subordinar importantes questões de princípio. Casos jurídicos constitucionais, por outro lado, podem provocar e de fato provocam uma ampla discussão pública que está focada na moralidade política (DWORKIN, 1996, p. 31, tradução nossa).

O ponto dessa citação é, como podemos perceber, fundamentar a pretensão de Dworkin de que uma corte exerce um tipo especial de discurso para cumprir a sua "responsabilidade política” de assegurar a prioridade dos argumentos de princípio sobre os argumentos de política (DWORKIN, 1977, p. 82), enquanto na política ordinária pode muito bem ser o caso de que leis carentes de “integridade” sejam aprovadas e os participantes tenham estabelecido “checkerboard laws” que são intrinsecamente imorais porque elas não fazem sentido sob qualquer esquema moral coerente de valores (DWORKIN, 1986, p. 179). Nem cortes e nem legisladores teriam legitimidade, segundo Dworkin, para recorrer a tais compromissos ao decidir questões de princípio.

O próprio Marmor reconhece que Dworkin tem razão ao criticar as denominadas “checkerboard laws”, que são carentes de justificação à luz de qualquer concepção moral coerente. Não obstante, parece ser o caso de que a conclusão de Dworkin é excessivamente forte. Pode-se argumentar, contra Dworkin, que essa visão acerca dos compromissos está baseada em preconceitos e não corresponde aos compromissos realmente existentes em um legislativo democrático.

O perigo de compromissos do tipo "checkerboard", que subordinam questões de princípio, é claramente inexistente quando os requisitos procedimentais da deliberação pública estão satisfeitos. No contexto de desacordos razoáveis, que inclui “posições conflituosas e incomensuráveis”, Richard Bellamy oferece uma visão menos cética sobre compromissos políticos. Ele pensa que compromissos não devem ser considerados carentes de princípio e injustificáveis. Pelo contrário, eles são muitas vezes o resultado do "mútuo reconhecimento pelos cidadãos da razoabilidade de seus pontos de vista muitas vezes divergentes, ao tentar acomodar essas várias perspectivas em um programa de governo coerente” (BELLAMY, 2007, p. 192-193, tradução nossa).

Nessa concepção caridosa, compromissos sobre direitos são valiosos porque eles constituem um reforço à ideia de "não dominação" de quaisquer cidadãos e reforçam o valor do "Estado de direito” (BELLAMY, 2007, p. 194, tradução nossa).

O ideal de integridade legislativa deveria ser substituído, portanto, como Marmor nos adverte, por um princípio político mais brando e capaz de preservar e proteger o pluralismo de 
concepções políticas e morais existente em nossa sociedade, abrindo mão ocasionalmente da busca de coerência moral em troca de uma maior proteção aos procedimentos de deliberação e decisão democráticos exigidos pela equidade e pelo ideal político de democracia.

A nosso ver, talvez o próprio Dworkin pudesse aceitar essa sugestão de diminuir o espectro do ideal político de "integridade”, substituindo-o pela exigência mais modesta de que o legislador crie leis com a “responsabilidade moral” de garantir igual respeito pela independência ética de cada indivíduo e grupo na comunidade política, para viver de acordo com os valores que cada um deles considere dignos de uma vida boa. O ideal de “democracia como parceria”, defendido pelo próprio Dworkin, ao exigir “igual respeito e consideração por todas as partes” que atuam no âmbito da política (DWORKIN, 2011, p. 384, tradução nossa), parece se coadunar mais com essa exigência modesta de responsabilidade moral do que com uma pretensão ambiciosa de coerência no âmbito da escolha dos valores morais que definirão os ramos da política em nossa comunidade.

Marmor tem uma parcela importante de razão, portanto, ao sustentar que a integridade não consegue desempenhar o papel que Dworkin lhe atribui no âmbito da elaboração de normas gerais pelo poder legislativo, pois é um valor alcançado a um custo moral proibitivo, já que concorre com importantes princípios ligados ao aspecto procedimental da democracia e à alternância de poder que é própria do pluralismo no âmbito da moral e da política contemporânea. É justamente a exigência de evitar um approach do tipo “winner takes all” e de não deixar nenhuma concepção de justiça razoável à margem do processo político - isto é, “abandonada no campo de batalha” - que torna valiosos os compromissos que Dworkin parece inadmitir com o seu ideal de integridade legislativa.

\section{CONCLUSÃO}

Podemos sustentar que Dworkin persegue um objetivo valioso ao advogar a integridade no âmbito da legislação (e não apenas da aplicação judicial do direito). Dworkin busca, com o apelo a esse ideal, defender um compromisso da nossa comunidade política com a nossa história institucional e com os juízos e princípios morais formulados na nossa tradição e objeto de um amplo comprometimento por parte de nossa comunidade. A exigência de coerência moral contida no ideal de "integridade" pode, no entanto, constituir um perigoso pretexto para o conservadorismo e o imobilismo no âmbito da moralidade política, colocando em xeque exigências importantes do ideal de "Estado de direito" e da democracia, que estão ligadas ao pluralismo político e moral característico da nossa sociedade e à benévola alternância de poder que é própria das sociedades democráticas. 
Por conseguinte, embora Dworkin esteja inequivocamente correto ao estabelecer para o legislador uma responsabilidade moral e uma obrigação de igual respeito e consideração por todos os indivíduos e grupos sociais existentes na polis, talvez o ideal de integridade no legislativo seja excessivamente custoso e perigoso para as democracias contemporâneas.

\section{REFERÊNCIAS}

BELLAMY, Richard. Political Constitutionalism: A Republican Defence of the Constitutionality of Democracy. Cambridge: Cambridge University Press, 2007.

DWORKIN, Ronald. Freedom's Law: The Moral Reading of the American Constitution. Cambridge, MA: Belknap, 1996.

DWORKIN, Ronald. A Matter of Principle. Cambridge, MA: Belknap, 1985.

DWORKIN, Ronald. Justice for Hedgehogs. Cambridge, MA: Belknap, 2011.

DWORKIN, Ronald. Law’s Empire. Cambridge, MA: Belknap, 1986.

DWORKIN, Ronald. Taking Rights Seriously. Cambridge, MA: Belknap, 1977.

GUEST, Stephen. Ronald Dworkin. Stanford: Stanford University Press, 2012.

MARMOR, Andrei. Should We Value Legislative Integrity? In: BAUMAN, Richard W.; KAHANA, Tsvi (Org.). The Least Examined Branch: The Role of Legislatures in the Constitutional State. Cambridge: Cambridge University Press, p. 125-139, 2006.

RAZ, Joseph. La ética en el ámbito público. Barcelona: Gedisa, 1994.

RAZ, Joseph. Practical Reason and Norms. 2. ed. Oxford: Oxford University Press, 1999.

RAZ, Joseph. Speaking with One Voice: On Dworkinian Integrity and Coherence. In: BURLEY, Justine (Org.). Dworkin and his critics: With replies by Dworkin. Oxford: Blackwell Publishing, p. 285-290, 2004.

WALDRON, Jeremy. Law and Disagreement. Oxford: Oxford University Press, 1999.

Thomas da Rosa de Bustamante Professor de Filosofia do Direito da Universidade Federal de Minas Gerais (UFMG). Bolsista de Produtividade em Pesquisa do CNPq, Nível 2. E-mail: thomas_bustamante@yahoo.com.br 